\title{
Morfologia externa dos estágios imaturos de heliconíneos neotropicais. III. Heliconius erato phyllis (Fabricius) (Lepidoptera, Nymphalidae, Heliconiinae) ${ }^{1}$
}

\author{
Lucas A. Kaminski ${ }^{2}$ \\ Maurício Tavares ${ }^{2}$ \\ Viviane G. Ferro ${ }^{2}$ \\ Gilson R.P. Moreira ${ }^{2,3}$
}

\begin{abstract}
External morphology of the immature stages of neotropical heliconians. III. Heliconius erato phyllis (Fabricius) (Lepidoptera, Nymphalidae, Heliconiinae). The external features of egg, larva and pupa of Heliconius erato phyllis (Fabricius, 1775) are described and illustrated, based upon light and scanning electron microscopy
\end{abstract}

KEY WORDS. Lepidoptera, Heliconiini, Nymphalidae, immature stages, morphology

Heliconius Kluk, 1802 (Lepidoptera, Nymphalidae) é um dos gêneros mais conspícuos e conhecidos de borboletas neotropicais (DEVRIES 1987). Heliconius erato (Linnaeus, 1758) é considerada a espécie mais variável do gênero, sendo reconhecidas, até o presente, 29 subespécies (HOLZINGER \& HOLZINGER 1994). Segundo os mesmos autores, Heliconius erato phyllis (Fabricius, 1775) apresenta ampla distribuição na América do Sul, onde ocorre desde o nordeste até o sul do Brasil, Bolívia, nordeste da Argentina e Uruguai.

Heliconius erato é comumente encontrada em ambientes ensolarados, sendo freqüente em florestas abertas ou perturbadas, bem como clareiras em florestas densas (BROWN 1992). Os adultos possuem comportamento semigregário, formando agrupamentos noturnos chamados de "dormitórios" que reúnem de 2 a 145 indivíduos (Crane 1957; Turner 1971; Mallet 1986; R. DiMare, UFRGS, dados não publicados). O ovo é depositado na região apical dos ramos de várias espécies de Passiflora Linnaeus, preferencialmente do subgênero Plectostemma Masters. A larva é solitária e apresenta tendência ao canibalismo (BROWN \& MielKe 1972; Benson et al. 1976). As espécies de Heliconius, devido à fácil adaptação às condições de insetário e cultivo de suas plantas hospedeiras, têm sido utilizadas como modelos experimentais em diversos estudos sobre interação inseto-planta (e.g. GILBERT 1971, 1975; BENSON et al. 1976; SPENCER

1) Contribuição número 378 do Departamento de Zoologia, Universidade Federal do Rio Grande do Sul.

2) Departamento de Zoologia, Instituto de Biociências, Universidade Federal do Rio Grande do Sul. Avenida Bento Gonçalves 9500, 91501-970 Porto Alegre, Rio Grande do Sul, Brasil.

3) E-mail: gilson.moreira@ ufrgs.br 
1988; Mugrabi-Oliveira \& Moreira 1996a,b), dentre outros aspectos, tais como mimetismo, biogeografia e ecologia (revistos por BENSON et al. 1976; BROWN 1981; GILBERT 1991).

O conhecimento morfológico dos estágios imaturos dos heliconíneos é escasso, limitando-se aos trabalhos pioneiros de BEEBE et al. (1960) e FLEMING (1960), para as espécies de Trinidad. Nesses estudos, foram abordados aspectos morfológicos gerais e a quetotaxia da larva de primeiro ínstar, respectivamente. Com o intuito de ampliar o conhecimento morfológico dos estágios imaturos dos heliconíneos neotropicais, uma série de estudos vem sendo desenvolvidos, dando-se ênfase à ultraestrutura tegumentar externa destes (ANTUNES et al. no prelo; TAVARES et al. 2002). Tal enfoque justifica-se uma vez que a utilização de características morfológicas dos estágios imaturos, somada a dos adultos, tem se mostrado de grande valia em estudos taxonômicos e/ou filogenéticos em Lepidoptera (e.g. Miller 1991; LeE et al. 1992; PENZ 1999).

Neste trabalho, caracteriza-se os estágios imaturos de $H$. erato phyllis com base na microscopia óptica e eletrônica de varredura. Dentre os seus objetivos específicos, destacam-se: descrição da ultraestrutura tegumentar externa do ovo, identificação morfométrica e quetotáxica dos ínstares larvais, e aspectos gerais e ultraestruturais da morfologia tegumentar externa da pupa.

\section{MATERIAL E MÉTODOS}

Os espécimes utilizados foram provenientes de adultos coletados no município de Viamão, Rio Grande do Sul. Após a captura, as borboletas permaneceram em insetário, com a presença de Passiflora suberosa Linnaeus para oviposição. O insetário era monitorado diariamente para alimentação dos adultos e coleta dos ovos (detalhes em Mugrabi-Oliveira \& Moreira 1996b). Parte dos ovos foi fixada em fluído de Dietrich e o restante permaneceu em placas de Petri com papel absorvente úmido até a eclosão. As larvas obtidas foram criadas em laboratório sobre ramos de $P$. suberosa. Os ramos eram mantidos em garrafas plásticas com suporte de arame, contendo água e cobertos por uma tela de malha fina. O desenvolvimento das larvas até pupa foi acompanhado diariamente. As cápsulas cefálicas (exúvias) eram recolhidas e os imaturos separados por ínstar, fixados em Dietrich e preservados em etanol a 70\%.

Os aspectos gerais dos imaturos foram analisados a partir de material fixado ou incluso em gelatina glicerinada. As cápsulas cefálicas foram reidratadas e montadas sob lâmina/lamínula, utilizando-se gelatina glicerinada como meio de inclusão. As ilustrações foram realizadas em uma lupa Spencer ${ }^{(B)}$ com o auxílio de uma grade micrométrica e obtidas através da comparação de, no mínimo, cinco exemplares. O padrão de coloração, em vivo, da larva de quinto ínstar e pupa foi representado em aquarela. Aspectos ultraestruturais foram observados num microscópio eletrônico de varredura, sendo as amostras preparadas de acordo com o seguinte protocolo: desidratação em ponto crítico utilizando-se aparelho Bal-tec ${ }^{(B)}$ - CPD030, montagem em suporte metálico com fita dupla face, cobertura com ouro num metalizador Bal-tec ${ }^{(B)}$ - SCD050, observação e fotografia num aparelho JEOL ${ }^{\circledR} 5800$. 
Na descrição do ovo, utilizou-se a nomenclatura proposta por BEEBE et al. (1960), HINTON (1981) e DOWNEY \& ALLYN (1981). A identificação das áreas do corpo da larva seguiu PETERSON (1962). Para a quetotaxia primária usou-se a de FLEMING (1960) e STEHR (1987), que também foi utilizada na descrição do padrão dos ganchos do larvópodo. Para a descrição dos escolos foi adotado BEEBE et al. (1960) e, para a descrição da pupa, MOSHER (1916).

A largura da cápsula cefálica foi obtida com o auxílio de uma escala micrométrica acoplada a ocular de uma lupa Spencer ${ }^{\circledR}$, utilizando-se espécimes fixados em Dietrich. A medida se refere a maior largura em vista frontal. Os valores relativos foram ajustados pelo método dos mínimos quadrados à função $\mathrm{y}=\mathrm{ae}^{\mathrm{bx}}$ (SNEDECOR \& COCHRAN 1980).

\section{RESULTADOS E DISCUSSÃO}

\section{Ovo}

O ovo é subcilíndrico, apresentando o ápice afilado e a base achatada (Fig. 1). As dimensões (média \pm erro padrão) correspondentes à altura e ao diâmetro da base respectivamente foram, para 10 exemplares examinados, de $1,48 \pm 0,01$ e 0,8 $\pm 0,001 \mathrm{~mm}$. Esses resultados são similares aqueles de BEEBE et al. (1960). Da mesma forma, com relação à coloração, caracterizada como sendo amarelo ouro sem variação ao longo do desenvolvimento embrionário.

Conforme já descrito para outras espécies de heliconíneos (BEEBE et al. 1960; ANTUNES et al. no prelo), H. erato phyllis apresenta ovos divididos por carenas horizontais (Hr, Fig. 1) e verticais (Vr, Fig. 1). Nos espécimes estudados, estas variaram de 10 a 12 e de 14 a 15 , respectivamente. As carenas delimitam células de formato distinto, conforme sua posição, superior (Uc, Fig. 2) ou inferior (Lc, Fig. 3). As células inferiores são retangulares com os cantos internos arredondados, assim como as células superiores que são de formato pentagonal ou hexagonal. Todas apresentam superfície coberta por pequenas depressões, inclusive as carenas (Fig. 5). O aumento do número de vértices, somado à redução numérica de células em direção ao ápice, define o caráter afilado do ovo na região polar.

A região micropilar (Fig. 4), de formato côncavo, encontra-se no ápice do ovo (pólo anterior), de acordo com o obtido por HinTon (1981). O número de vértices desta, nos espécimes estudados, variou de quatro a sete. Em conseqüência, a região micropilar pode assumir um formato variável, de tetragonal a heptagonal, delimitando uma concavidade (Ap, Fig. 1). Na borda desta, encontram-se células com lados arredondados, e internamente, poligonais que convergem para o centro, onde se localizam as micrópilas (Mp, Fig. 4). DownEY \& ALLYN (1981) denominaram estas regiões de ânulo e roseta, respectivamente.

As aerópilas situam-se nos vértices de todas as células inferiores e superiores, sobre as carenas (Ac, Figs 2, 3, 5). São arredondadas com peritrema pouco delineado. As células do ânulo, adjacentes às células superiores, também possuem aerópilas. 

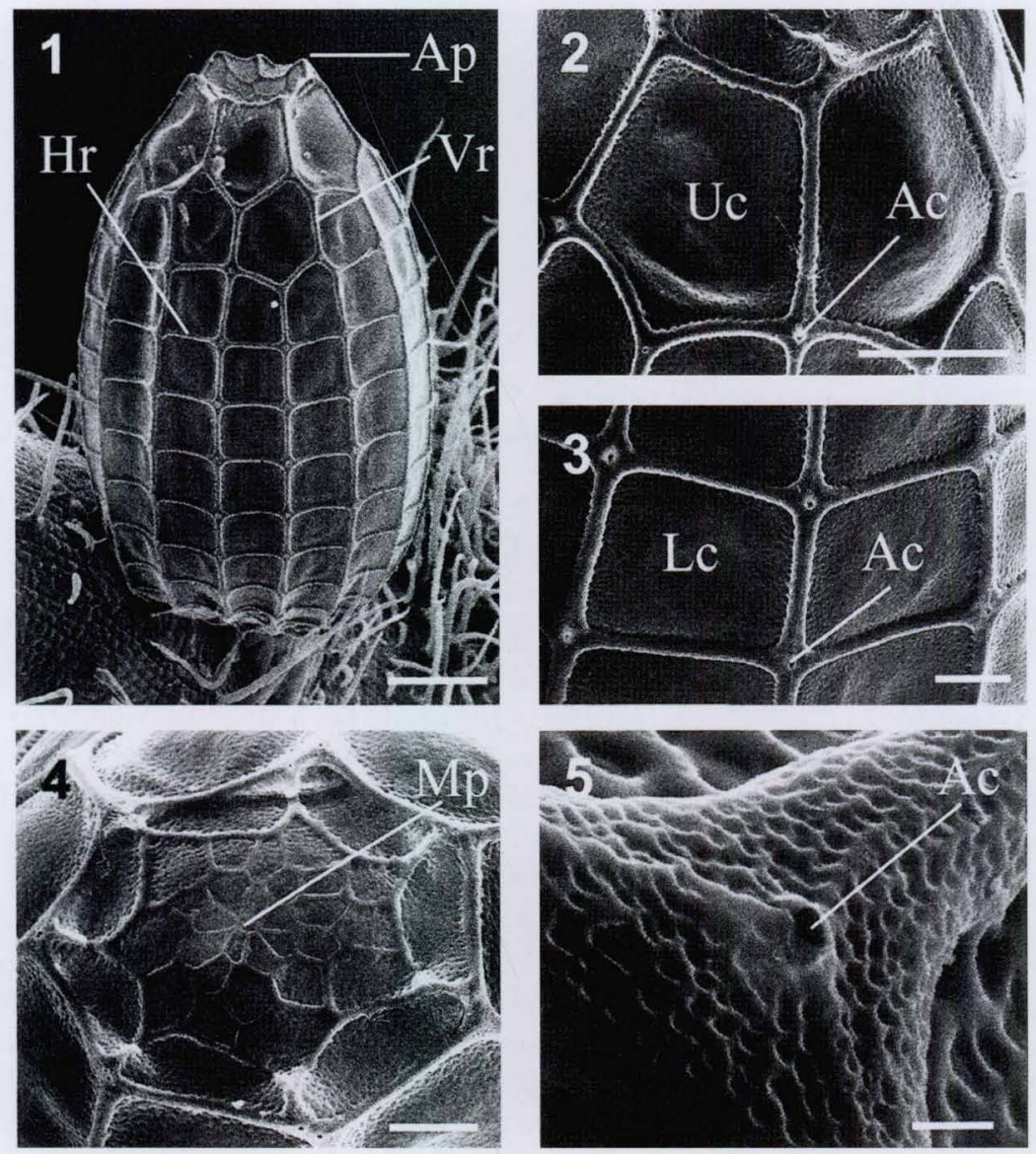

Figs 1-5. Ovo de $H$. erato phyllis em microscopia eletrônica de varredura: (1) vista látero-dorsal do ovo; (2) células superiores; (3) células inferiores; (4) região micropilar; (5) aerópila. (AC) Aerópila, (Ap) polo anterior, (Hr) carena horizontal, (Lc) célula inferior, (Mp) micrópilas, (Uc) célula superior, $(\mathrm{Vr})$ carena vertical. Barras $=250,100,50,100$ e $10 \mu \mathrm{m}$, respectivamente.

\section{Larva}

As larvas de heliconíneos seguem o padrão geral para Lepidoptera (STEHR 1987), e apresentam normalmente cinco ínstares larvais. Dentre os ínstares ocorrem mudanças significativas quanto ao desenvolvimento dos escolos e coloração. Como já relatado por BEEBE et al. (1960), o primeiro ínstar difere dos demais por apresentar cerdas primárias distribuídas pelo corpo (Figs 7, 9, 16).

No primeiro ínstar de $H$. erato phyllis, as cerdas da cápsula cefálica possuem coloração marrom-escura, sendo que as do frontoclípeo, labro e microcerdas são menores e semitransparentes. Na base das cerdas maiores, estão presentes pequenas áreas elevadas (calazas), esclerotinizadas e marrons. 


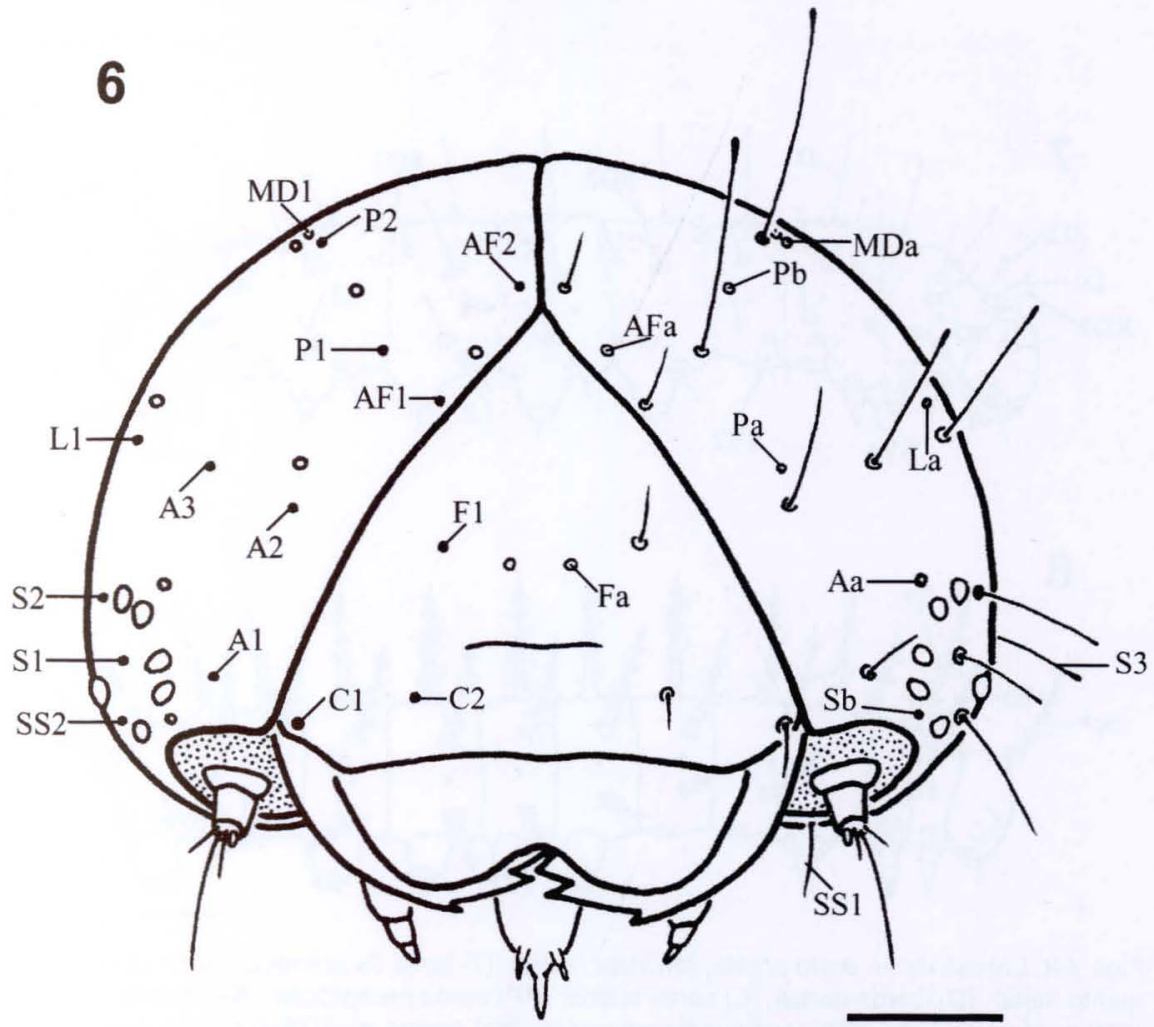

Fig. 6. Cápsula cefálica de larva de primeiro ínstar de $H$. erato phyllis, em vista frontal: (A) cerda anterior, (Aa) poro anterior, (AF) cerda adfrontal, (Afa) poro adfrontal, (C) cerda clipeal, (F) cerda frontal, (Fa) poro frontal, (L) cerda lateral, (La) poro lateral, (MD) microcerda dorsal, (MDa) poro dorsal, ( $\mathbf{P})$ cerda póstero-dorsal, $(\mathrm{Pa}$ e $\mathbf{P b})$ poros póstero-dorsais, (S) cerda subestematal, $(\mathrm{Sb})$ poro estematal, $(\mathrm{SS})$ cerda subestematal. Barra $=90 \mu \mathrm{m}$.

A fronte e o clípeo estão fusionados formando o frontoclípeo (STEHR 1987), sendo que o anteclípeo não é aparente, contrastando com outros heliconíneos (ANTUNES et al. no prelo; TAVARES et al. 2002). O labro cobre pouco mais da metade da mandíbula em vista frontal. Adjacente às mandíbulas, situa-se uma área membranosa eversível lisa, na qual se insere a antena (Fig. 15), que é constituída por três artículos: o primeiro alargado; o segundo alongado (An2), apresentando várias setas, sendo uma longa e as demais curtas; o terceiro é reduzido (An3) e apresenta três setas.

A quetotaxia da cápsula cefálica (Fig. 6) segue o descrito por FLEMING (1960), que citou a presença de um par de poros frontais (Fa, Fig. 6). No presente estudo, foi constatada a presença dos demais poros previstos pelo padrão geral sugerido por Stehr (1987): Aa, AFa, La, MDa, Pa, Pb, Sb (Fig. 6); MGa, Sa, SSa não são visíveis em vista frontal. Além desses poros, constatou-se a presença das microcerdas MD1, MD2 e MD3, consideradas proprioreceptores (STEHR 1987). A microcerda MD1 está posicionada entre a cerda $\mathbf{P 2}$ e o poro MDa (Fig. 6). As 

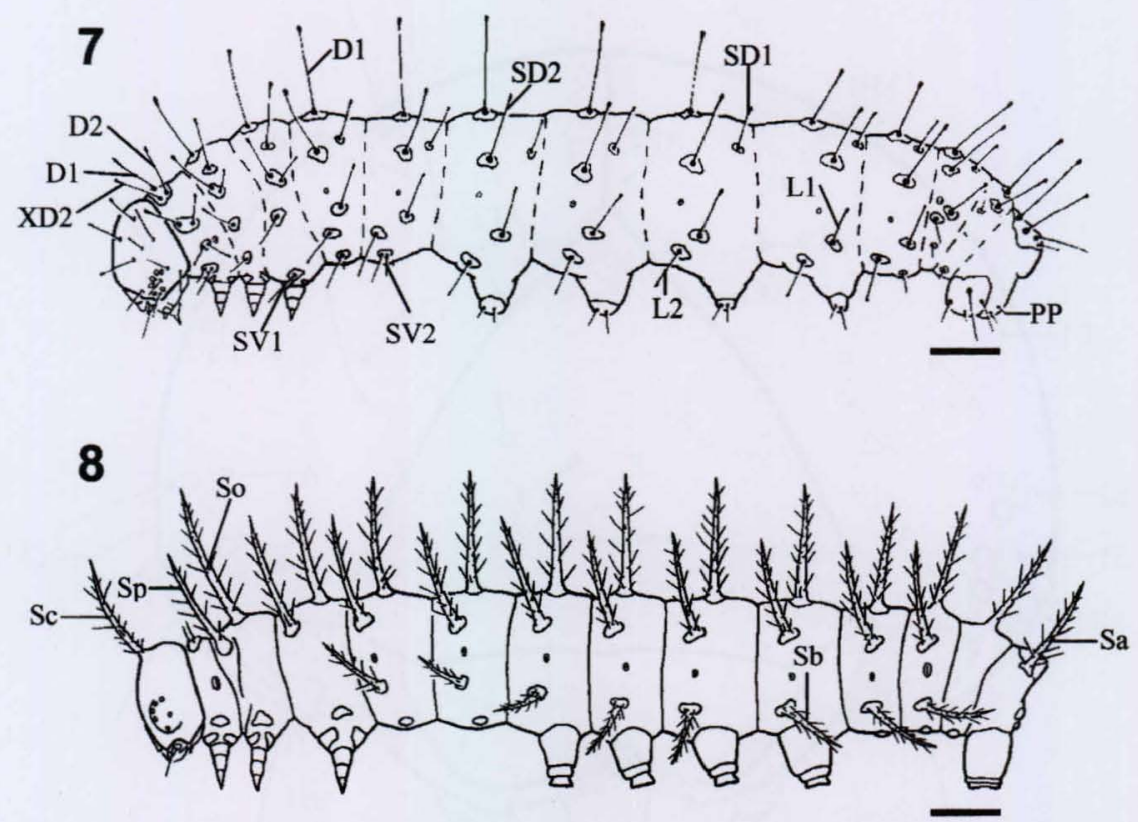

Figs 7-8. Larvas de $H$. erato phyllis, em vista lateral: (7) larva de primeiro instar; (8) larva de quinto ínstar. (D) Cerda dorsal, (L) cerda lateral, (PP) cerda paraproctal, (Sc) escolo cefálico, (SD) cerda subdorsal, (SI) escolo subespiracular, (Sn) escolo anal, (So) escolo dorsal, (Sp) escolo supraespiracular, (SV) cerda subventral. Barras $=0,2$ e $1 \mathrm{~mm}$, respectivamente.

microcerdas MD2 e MD3 estão situadas posteriormente ao poro MDa, e não são visíveis em vista dorsal. Nenhuma destas microcerdas havia sido observada nas espécies de heliconíneos estudadas por FLEMING (1960).

A caracterização ultraestrutural das cerdas demonstrou que a porção terminal destas pode ser dilatada ou afilada. A maioria das setas possuem a porção terminal dilatada (Fig. 17), com exceção de AF1, AF2, C1, C2, F1, SS1, SS2 e SS3 na cápsula cefálica (Fig. 6), e dos grupos subventral, ventral e paraproctal (senso BEEBE et al. 1960; STEHR 1987) no tórax e abdome (Fig. 7). Cerdas com porção terminal dilatada também são encontradas em Dryas iulia alcionea (Cramer, 1779) (A.C. Paim, dados não publicados). Porém, em outros heliconíneos a porção terminal das cerdas apresenta-se diferente; em Eueides isabella dianasa (Hübner, 1806) é afilada, e em Dione juno juno (Cramer, 1779) é partida (ANTUNES et al. no prelo; TAVARES et al. 2002).

A porção ventral do tórax e aquela próxima aos larvópodos (Fig. 19) apresentam-se cobertas por microtríquias (Fig. 20). Por conseguinte, difere de $D$. juno juno, onde as microtríquias estão distribuídas por todo o tórax e abdome (TAVARES et al. 2002). Os espiráculos (Fig. 18) possuem peritrema elevado, sendo que o torácico e o último abdominal são levemente maiores. 


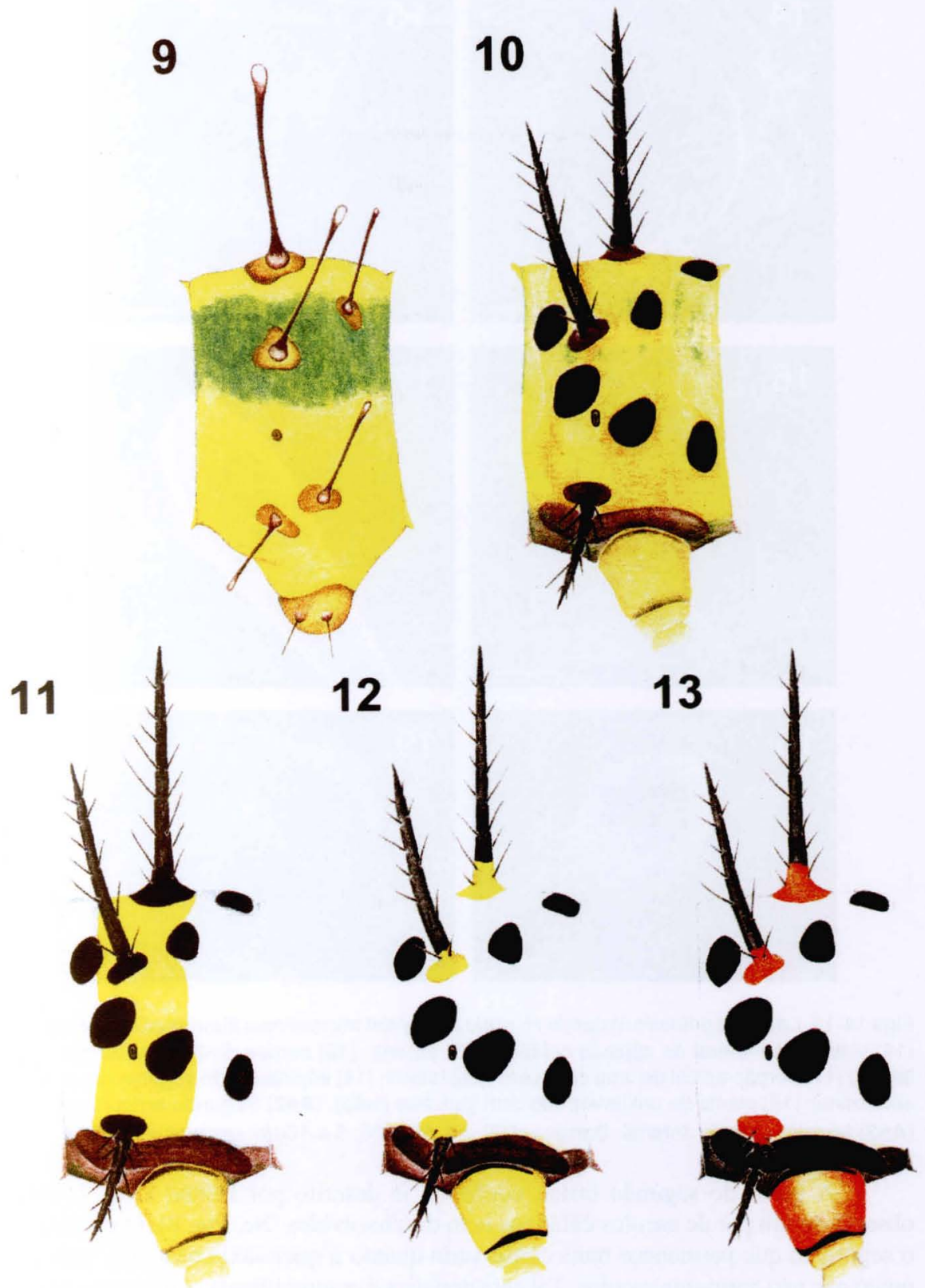

Figs 9-13. Representação esquemática da variação do padrão de coloração do quinto segmento abdominal de $H$. erato phyllis: (9) larva de primeiro ínstar; (10) larva de segundo ínstar; (11) larva de terceiro ínstar; (12) larva de quarto ínstar; (13) larva de quinto ínstar. 

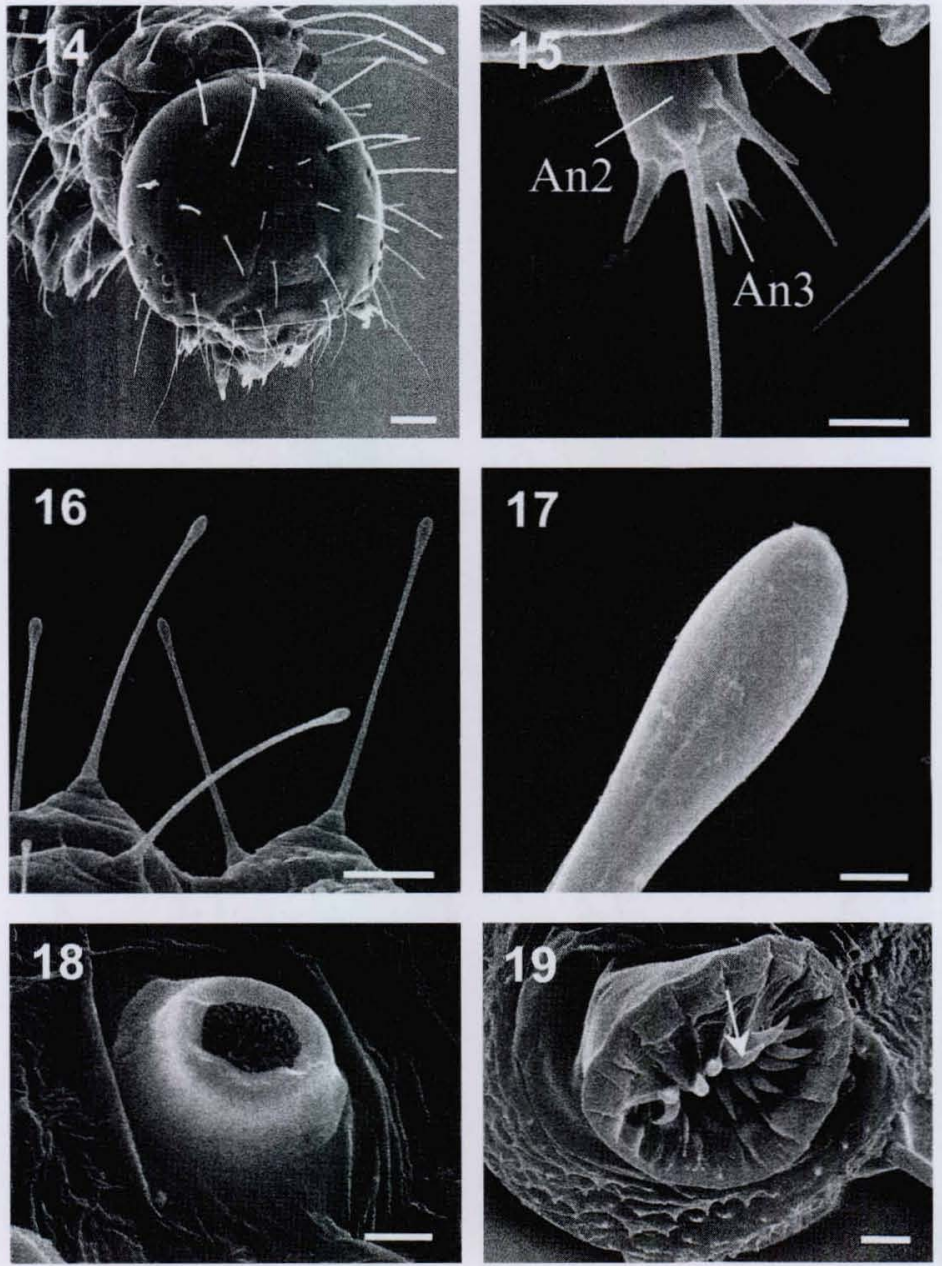

Figs 14-19. Larva de primeiro instar de $H$. erato phyllis em microscopia eletrônica de varredura: (14) vista dorso-lateral da cápsula cefálica; (15) antena; (16) cerdas do tipo calaza em vista lateral; (17) porção apical de uma cerda em vista lateral; (18) espiráculo do segundo segmento abdominal; (19) planta de um larvópodo com ganchos (seta). (An2) Segundo artículo antenal, (An3) terceiro artículo antenal. Barras $=100,10,50,100,5$ e 10 $\mu \mathrm{m}$, respectivamente.

A partir do segundo ínstar, conforme já descrito por BEEBE et al. (1960), observa-se um par de escolos cefálicos bem desenvolvidos (Sc, Fig. 8). O protórax é o segmento que permanece mais conservado quanto à quetotaxia primária, pois é o único que não apresenta escolos. Tal característica é compartilhada com a maioria dos heliconíneos, à exceção de D. juno juno (PENZ 1999; TAVARES et al. 2002). Os demais segmentos do tórax apresentam um par de escolos dorsais (So, Fig. 8) e outro supraespiracular (Sp, Fig. 8), e mantém as cerdas L1, SV1 e SV2. Do primeiro ao oitavo segmentos abdominais, verifica-se, em adição, um par de escolos subespiracu- 
lares (Sl, Fig. 8). Nestes segmentos, permanecem as cerdas subventrais da quetotaxia primária. Nono segmento abdominal com um par de escolos dorsais, cerdas subventrais e L1. Décimo segmento com um par de escolos anais (Sn, Fig. 8) (BEEBE et al. 1960), cerdas subventrais e paraproctais.

Porção distal do escolo apresenta-se como uma cerda tenuemente delimitada (Figs 22, 23), diferindo de $D$. juno juno que possui uma cerda com base de inserção côncava (TAVARES et al. 2002). As microtríquias (Fig. 21) tornam-se maiores e passam a cobrir quase todo o tegumento, principalmente no último ínstar. Espiráculos (Fig. 24) apresentam peritrema elíptico.

No primeiro ínstar, os ganchos do larvópodo (Fig. 19) são uniordinais e unisseriais. No quinto ínstar (Fig. 25), são unisseriais e triordinais.

\section{Identificação dos ínstares}

Para a identificação dos ínstares foram utilizados parâmetros morfológicos (coloração) e morfométricos (largura da cápsula cefálica).

No primeiro ínstar (Fig. 9), H. erato phyllis apresenta coloração amarelo ouro semelhante ao ovo. Após a alimentação, observa-se o conteúdo intestinal por transparência, gerando uma faixa verde ao longo do corpo. No segundo, a coloração é amarela (Fig. 10), porém mais escura que no primeiro ínstar, e com coloração esverdeada menos intensa no dorso, após a alimentação. Escolos de base marrom. Cada segmento abdominal, do primeiro ao oitavo, com seis pares de manchas pretas e barra subventral marrom-esverdeada. No terceiro ínstar, a cor predominante é o branco-azulado (Fig. 11), enquanto a coloração amarela restringe-se a uma faixa transversal mediana que abrange mais da metade do segmento e a base dos escolos preta. Neste ínstar as manchas pretas são bem delimitadas permanecendo desta forma até o quinto ínstar. Barra subventral marrom. No quarto ínstar, a cor predominante é a branca (Fig. 12), sem a faixa transversal amarela do ínstar anterior. Barra subventral marrom-escura e a base dos escolos amarelada. No quinto ínstar, a cor predominante é a branca (Figs 13, 46). Base dos escolos vermelho alaranjada e barra subventral preta.

As medidas referentes à largura da cápsula cefálica são apresentadas na tabela I. O crescimento da cápsula cefálica seguiu a regra de Brooks-Dyar, sendo obtida a seguinte equação exponencial de ajuste: $\ln y=0,460 x-1,036 ; r=0,99 ; n=120 ; p=$ 0,0001. A razão de crescimento da cápsula cefálica foi em média 1,59 entre os ínstares. Não houve sobreposição das medidas da largura da cápsula cefálica entre os ínstares, e dessa forma, tal critério pode ser adotado com segurança para a identificação desses.

Tabela I. Média aritmética e erro padrão, intervalo de variação e razão de crescimento da largura da cápsula cefálica dos instares larvais de Heliconius erato phyllis, criados sobre Passiflora suberosa. $n=24$ /instar.

\begin{tabular}{cccc}
\hline \multirow{2}{*}{ Ínstar } & \multicolumn{3}{c}{ Largura da cápsula cefálica $(\mathrm{mm})$} \\
\cline { 2 - 4 } & Média \pm erro padrão & Intervalo de variação & Razão de crescimento \\
\hline I & $0,55 \pm 0,006$ & $0,52-0,59$ & - \\
II & $0,90 \pm 0,010$ & $0,85-0,96$ & 1,63 \\
III & $1,44 \pm 0,021$ & $1,36-1,59$ & 1,60 \\
IV & $2,20 \pm 0,021$ & $2,08-2,49$ & 1,52 \\
V & $3,50 \pm 0,039$ & $3,32-3,74$ & 1,59 \\
\hline
\end{tabular}



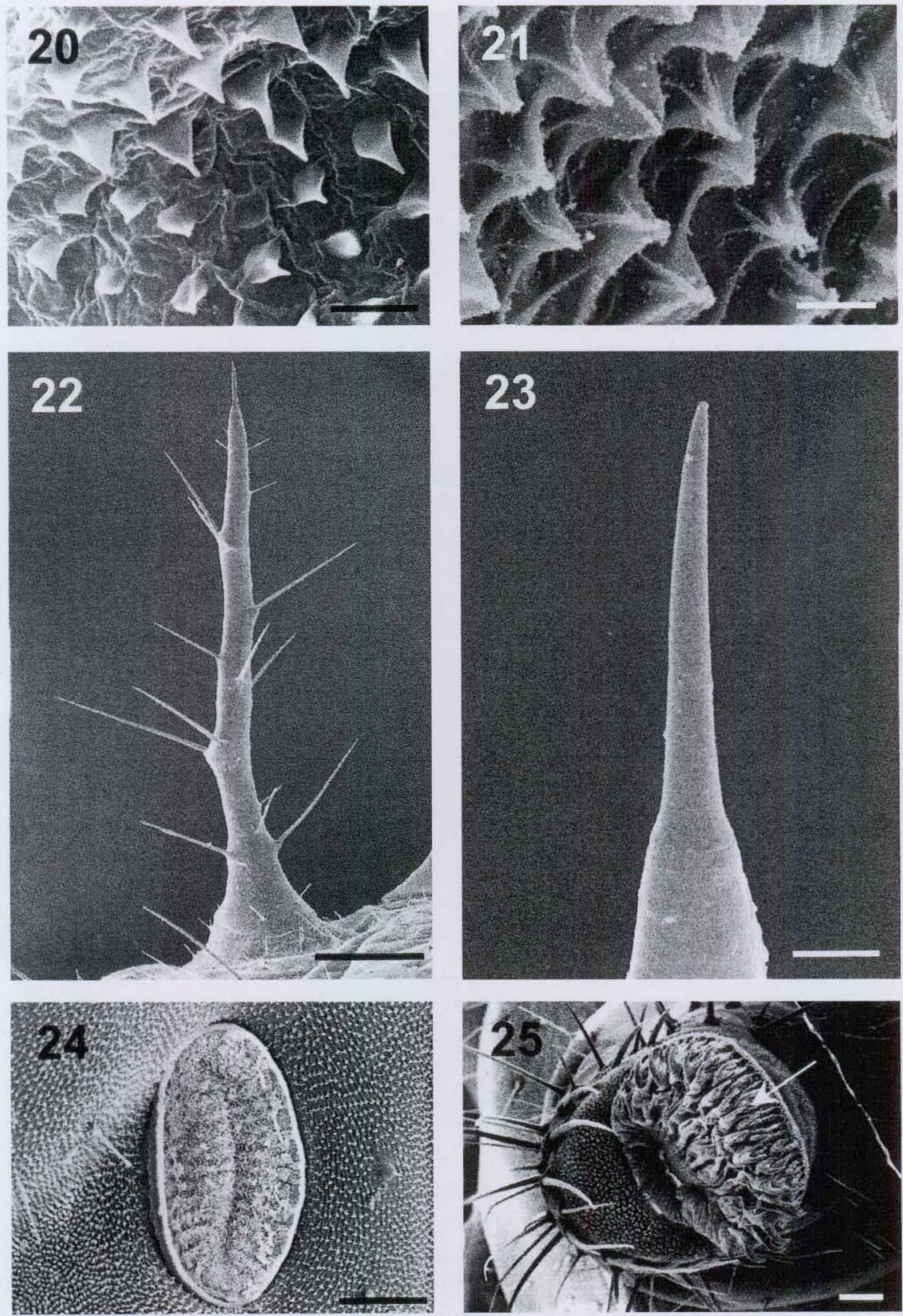

Figs 20-25. Larva de H. erato phyllis em microscopia eletrônica de varredura: (20) microtríquias da larva de primeiro instar; (21) microtríquias da larva de quinto ínstar; (22) escolo da larva de quinto ínstar; (23) porção terminal de um escolo de quinto ínstar; (24) espiráculo abdominal de larva de quinto ínstar; (25) planta de um larvópodo com ganchos (seta). Barras $=5,5,500$, 50,100 e $100 \mu \mathrm{m}$, respectivamente. 


\section{Pupa}

Assim como outros Nymphalidae observados (MOSHER 1916; TAVARES et al. 2002), as pupas de $H$. erato phyllis também se caracterizam pela ausência da sutura epicranial e pela posição das pernas pro- e mesotorácicas que tocam a margem posterior da região ocular (Fig. 26).

A coloração da pupa (Fig. 47) muda com a ontogênese, variando de marrom clara a marrom escura. O olho se constitui de duas áreas distintas: a primeira, de aspecto reluzente (Gr, Fig. 30), e a segunda de aspecto corrugado (Sr, Fig. 30) e com cerdas (Fig. 32). Labro (Lb, Fig. 26) posterior ao clípeo (Cl, Fig. 26) e entre as mandíbulas (Md, Fig. 28). Maxilas (Mx, Fig. 28) que estendem até a porção distal das antenas. A área correspondente à antena apresenta projeções em forma de espinhos (Fig. 31). Em contraponto, as de D. juno juno são pouco pronunciadas e de formato arredondado (tubérculos), e em E. isabella dianasa encontram-se ausentes (ANTUNES et al. no prelo; TAVARES et al. 2002). Projeções cefálicas (Cp, Figs 26, 29) longas, achatadas dorso-ventralmente e com a borda interna recortada. Próximo à inserção das projeções cefálicas, o tegumento possui estrias (Fig. 33).

Pernas protorácicas (Le1, Fig. 26) equivalem a menos da metade das mesotorácicas (Le2, Fig. 26). Pernas mesotorácicas com um par de tubérculos na região mediana. Pernas metatorácicas não são visíveis, pois encontram-se encobertas pelas asas. Na base das asas anteriores, estão presentes duas projeções (Fig. 36); a crista longitudinal (Bl) e o tubérculo basilar (Bt). Os tubérculos submarginais (St, Fig. 37), situam-se na margem externa da asa anterior (senso BEEBE et al. 1960).

Heliconius erato phyllis apresenta manchas douradas no protórax, metatórax e no primeiro e segundo segmentos abdominais (Fig. 47). Dorsalmente, são visíveis três linhas de tubérculos (Fig. 27); uma médio-dorsal (Mt) e um par de linhas látero-dorsais (Lt), formados pelos tubérculos correspondentes. Os tubérculos médio-dorsais (Fig. 41) estão presentes no quinto, sexto e sétimo segmentos abdominais. Os látero-dorsais (Figs 34, 35) são observados do protórax ao oitavo segmento abdominal. No terceiro, quarto e sexto segmentos abdominais os tubérculos látero-dorsais apresentam-se alongados na base, sendo que entre o terceiro e o quarto estão fusionados (Fig. 40). Os tubérculos ventrais encontramse no quinto e sexto segmentos abdominais (Fig. 27). A linha supraespiracular de tubérculos está presente no terceiro e quarto segmentos abdominais, sendo estes pouco pronunciados (Fig. 42).

Espiráculos presentes no protórax e do primeiro ao oitavo segmentos abdominais. A abertura do espiráculo mesotorácico (Figs 38, 39) está situada entre os segmentos pro- e mesotorácico. Primeiro espiráculo abdominal está encoberto pelas asas; demais, apresentam peritrema com formato elíptico (Fig. 43).

Cremáster (Fig. 44) de formato subtriangular, achatado ventralmente, com inúmeros ganchos de extremidade curvada em direção à base e subdividida em duas pontas (Fig. 45). 


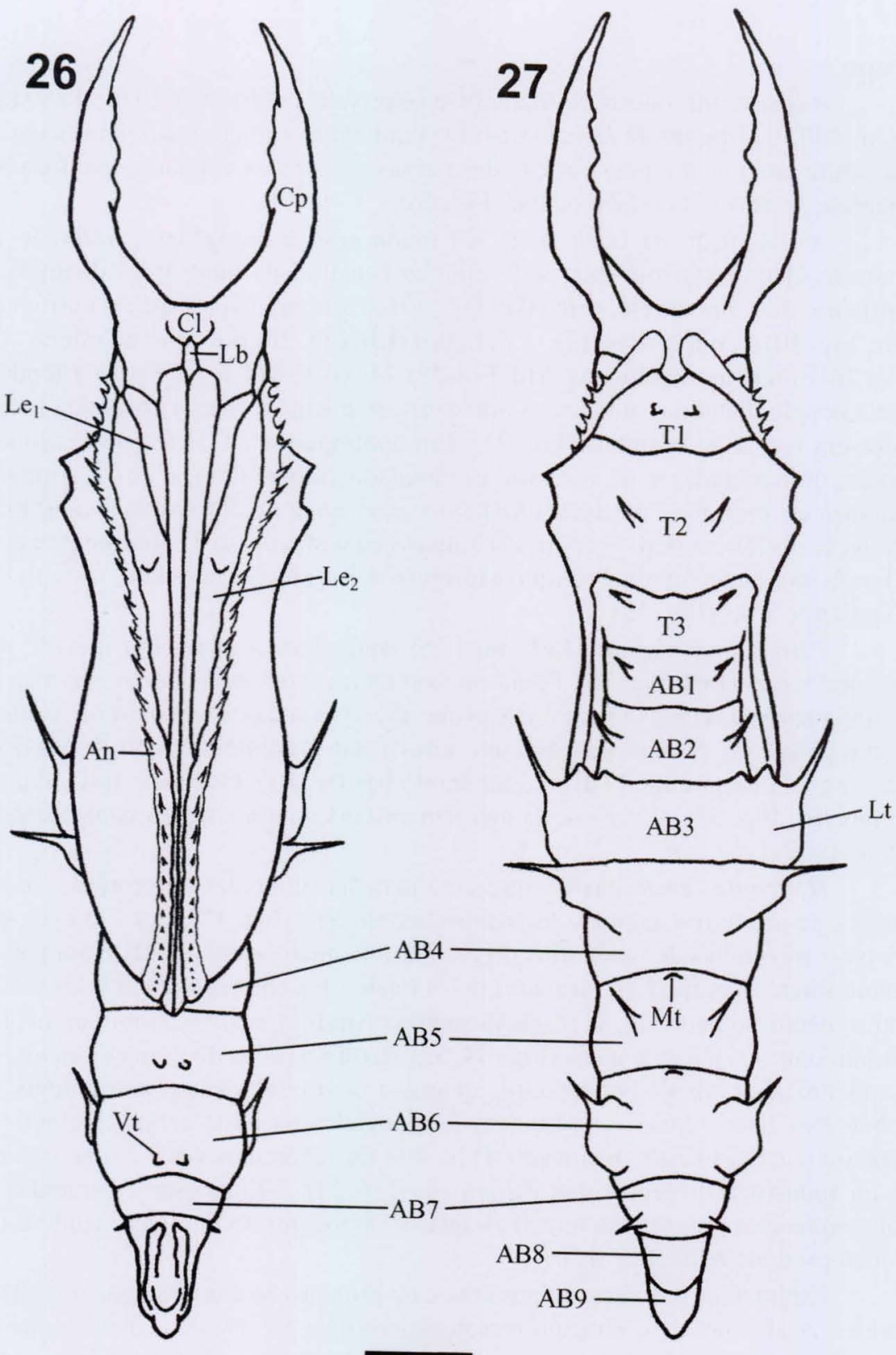

Figs 26-27. Pupa de $H$. erato phyllis: (26) vista ventral; (27) vista dorsal. (AB) Segmento abdominal, (An) antena, (Cl) clípeo, (Cp) projeção cefálica, (Lb) labro, (Le1) perna protorácica, (Le2) perna mesotorácica, (Lt) tubérculo lateral, (Mt) tubérculo médio-dorsal, (T) segmento torácico, $(\mathrm{Vt})$ tubérculo ventral. Barra $=1,8 \mathrm{~mm}$. 

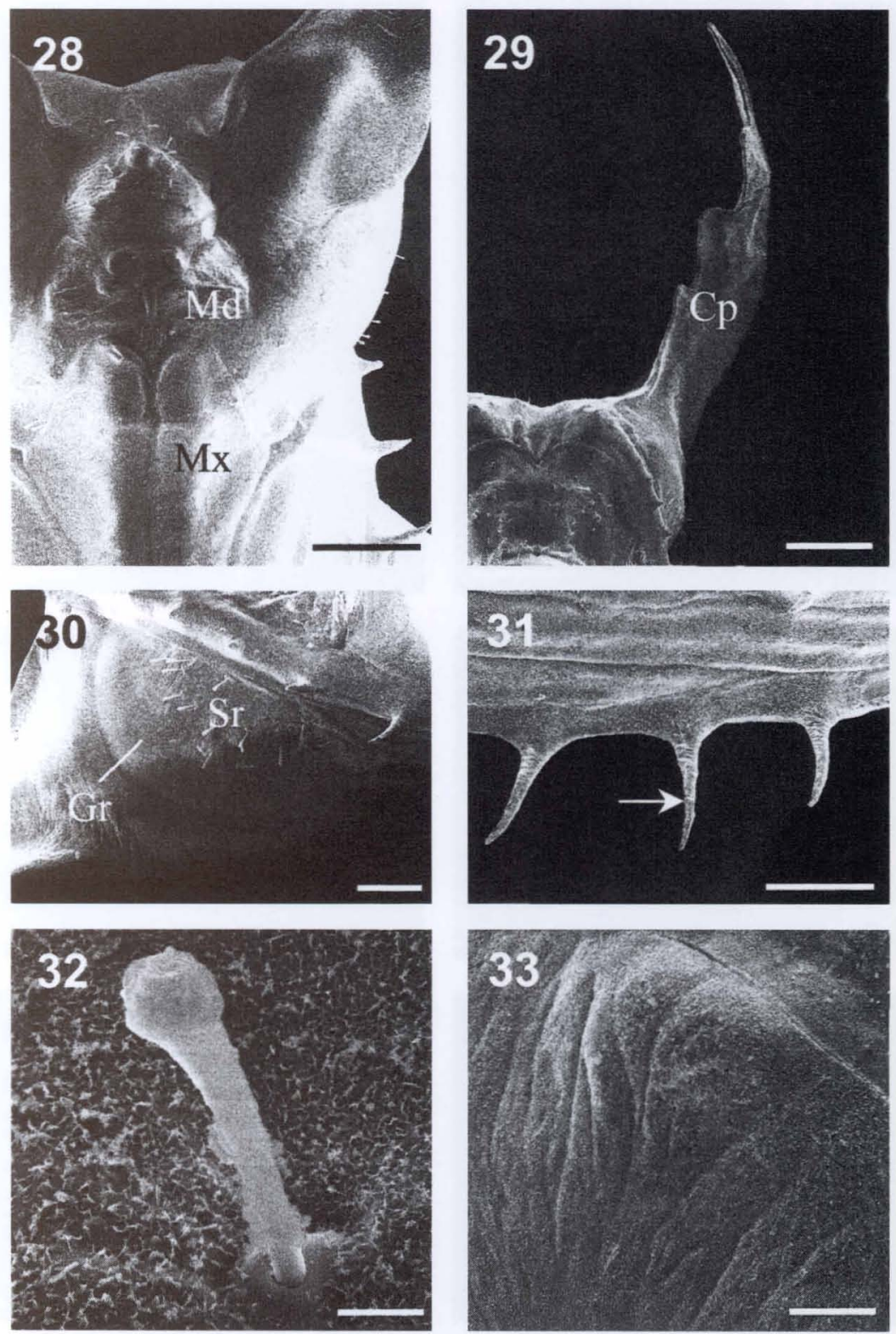

Figs 28-33. Pupa de $H$. erato phyllis em microscopia eletrônica de varredura: (28) cabeça em vista ventral; (29) projeção cefálica em vista dorsal; (30) cabeça em vista lateral; (31) porção mediana da antena em vista lateral, com tubérculos (seta); (32) detalhe de uma cerda da região ocular; (33) detalhe do tegumento próximo a projeção cefálica. (Cp) Projeção cefálica, (Gr) faixa de aspecto reluzente do olho, (Md) mandíbula, (Mx) porção proximal da máxila, (Sr) porção esculturada do olho. Barras $=0,5 ; 1 \mathrm{~mm}$ e $400,400,20,50 \mu \mathrm{m}$, respectivamente. 

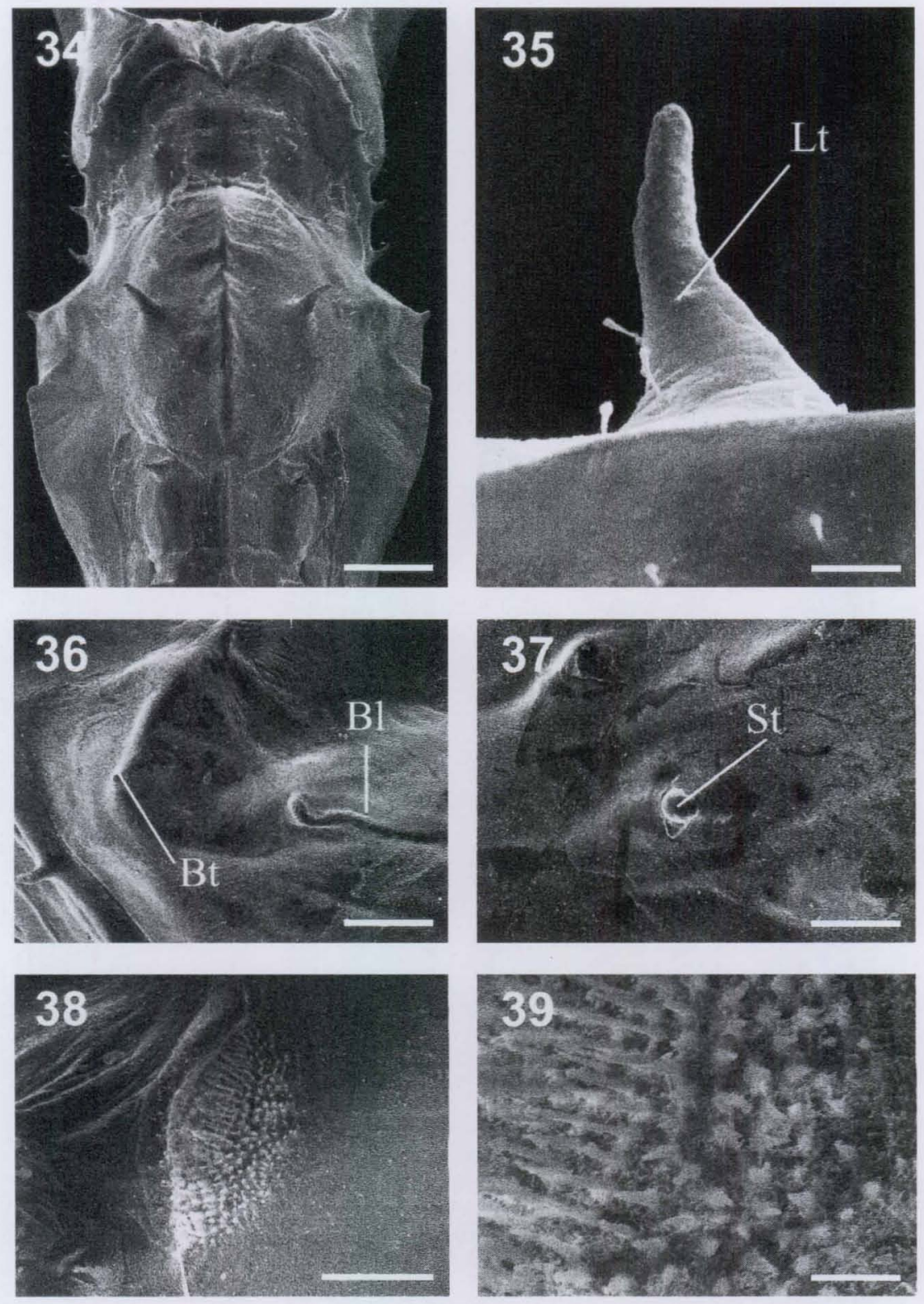

Figs 34-39. Pupa de H. erato phyllis em microscopia eletrônica de varredura: (34) cabeça e segmentos torácicos em vista dorsal; (35) tubérculo lateral do primeiro segmento torácico; (36) vista lateral da porção proximal da asa anterior; (37) vista lateral da asa; (38) espiráculo mesotorácico; (39) detalhe da abertura do espiráculo mesotorácico. (BI) Crista longitudinal, (Bt) tubérculo basilar, (Lt) tubérculo lateral, (St) tubérculo submarginal. Barras $=1 \mathrm{~mm}, 100$, $500,200,100$ e $20 \mu \mathrm{m}$, respectivamente. 

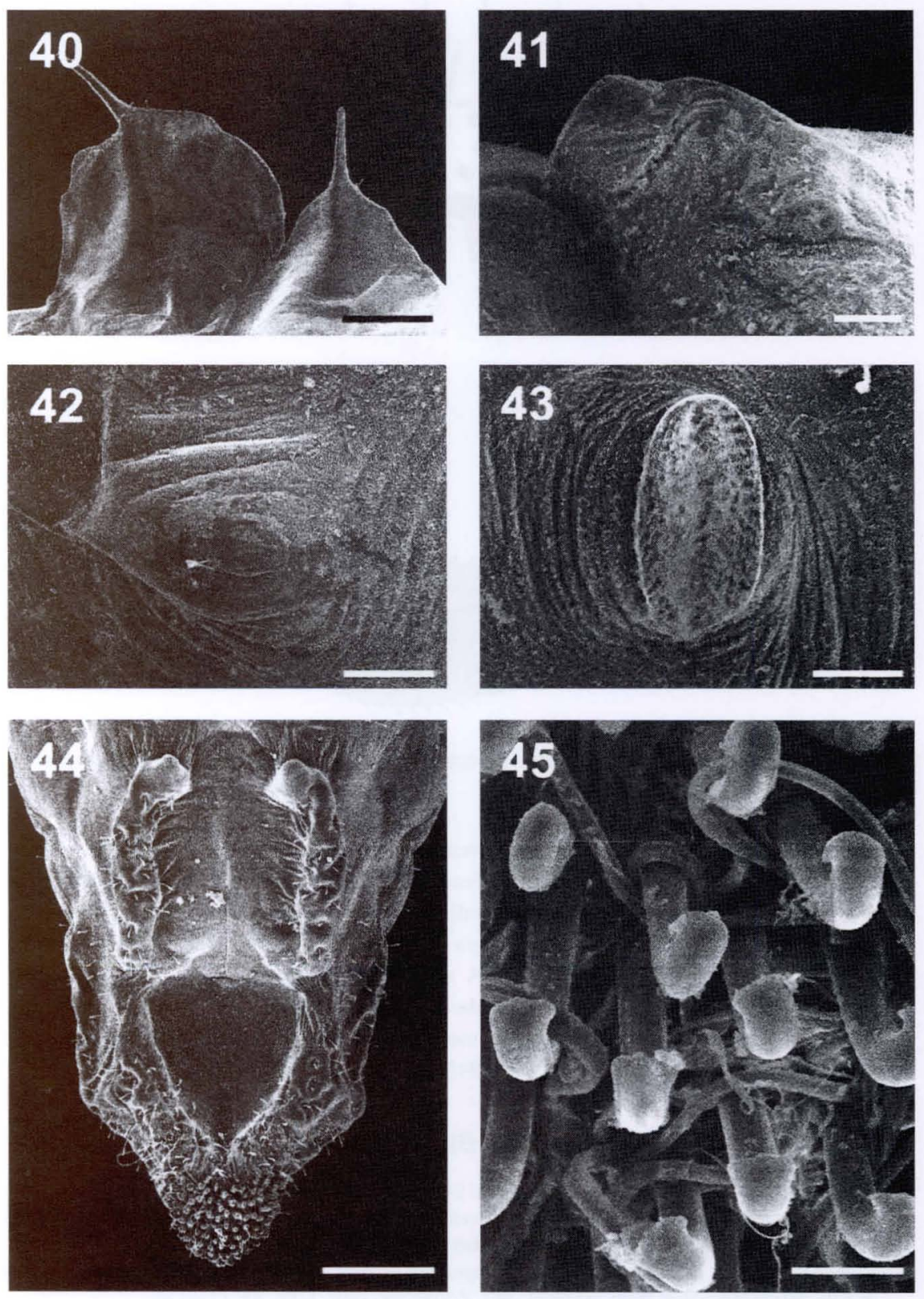

Figs 40-45. Pupa de $H$. erato phyllis em microscopia eletrônica de varredura: (40) tubérculos laterais do terceiro e quarto segmentos abdominais, em vista dorsal; (41) tubérculo médiodorsal do sexto segmento abdominal, em vista lateral; (42) tubérculo supraespiracular; (43) espiráculo do quinto segmento abdominal; (44) cremáster, em vista ventral; (45) ganchos do cremáster. Barras $=500,100,100,50,500,50 \mu \mathrm{m}$, respectivamente. 

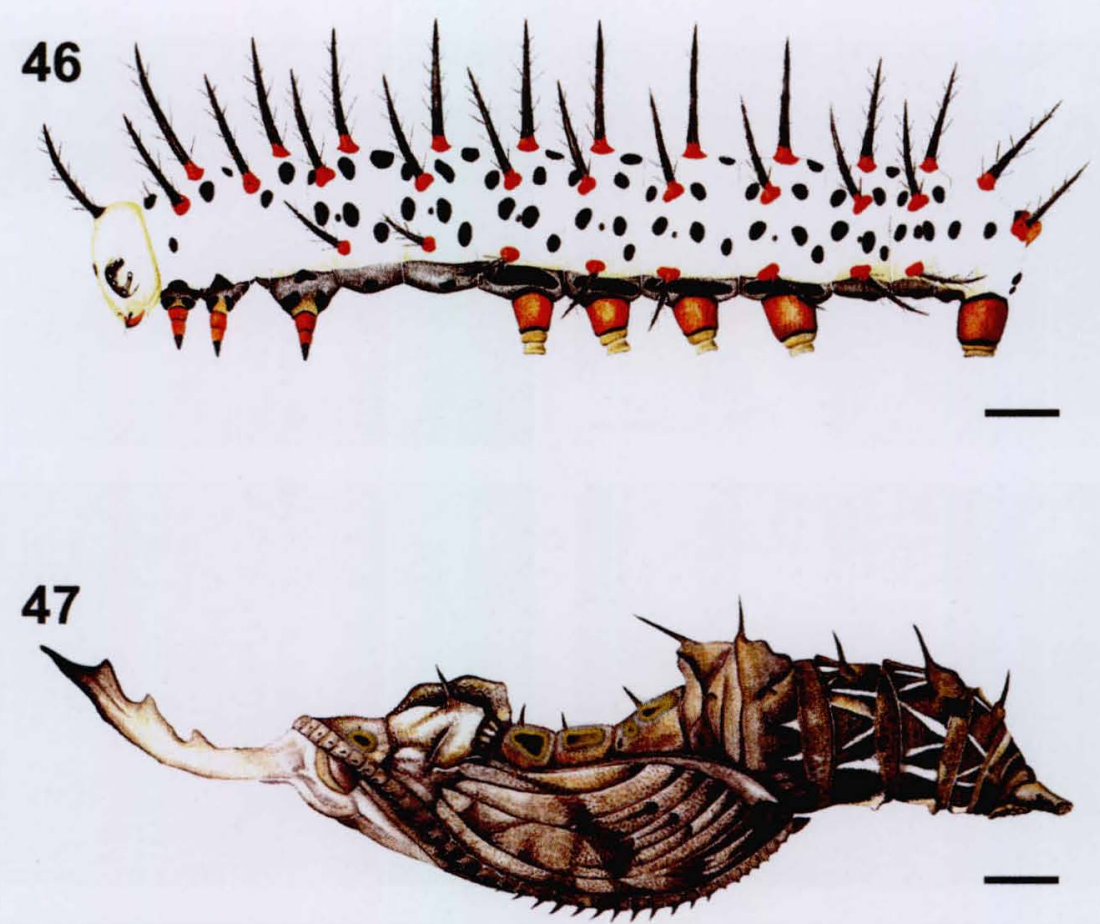

Figs 46- 47. Padrão de coloração da larva de quinto ínstar (46), e pupa (47) de $H$. erato phyllis. Barras $=1$ e 2,2mm, respectivamente. ।

AGRADECIMENTOS. Os autores agradecem ao Centro de Microscopia Eletrônica da UFRGS, especialmente a Christiane Lopes, Francis Farret Darsie e Miriam Souza dos Santos pelo auxílio na preparação das amostras e realização das fotos. Da mesma forma, a Mônica Fagundes Acioli, do Laboratório de Morfologia e Comportamento de Insetos da UFRGS, pelo constante apoio no decorrer do trabalho. A versão final do manuscrito foi grandemente beneficiada por críticas e sugestões efetuadas por Marcelo Duarte (UFPR) e um revisor anônimo. Este projeto foi parcialmente mantido por recursos provenientes da PROPESQ/UFRGS, FAPERGS (projeto n 94/50941.7) e do CNPq, concedidos a G.R.P. Moreira.

\section{REFERÊNCIAS BIBLIOGRÁFICAS}

Antunes, F.F.; A.O. Menezes JR.; M. TAVARes \& G.R.P. Moreira (no prelo). Morfologia externa dos estágios imaturos de heliconíneos neotropicais: I - Eueides isabella dianasa (Hübner, 1806) (Lepidoptera: Nymphalidae: Heliconiinae). Revta bras. Ent., Curitiba.

BeEbe, W.; J. Crane \& H. Fleming. 1960. A comparison of eggs, larvae and pupae in fourteen species of heliconiine butterflies from Trinidad, W.I. Zoologica, New York, 45: 111-154.

Benson, W.W.; K.S. BRown JR. \& L.E. GILBERT. 1976. Coevolution of plants and herbivores: passion flowers butterflies. Evolution, Bolder, 29: 659-680.

Brown Jr., K.S. 1981. The biology of Heliconius and related genera. Ann. Rev. Entomol., Stanford, 26: $427-456$.

- 1992. Borboletas da Serra do Japí: diversidade, hábitats, recursos alimentares e variação temporal. p. 142-187 In: L.P.C. MoRelLATo (Ed.) História Natural da Serra do Japí: Ecologia e

Revta bras. Zool. 19 (4): 977 - 993, 2002 
preservação de uma área florestal no sudeste do Brasil. Campinas, Unicamp/Fapesp, 322p.

BRown JR., K.S. \& O.H.H. MieLKE. 1972. The heliconians of Brazil (Lepidoptera: Nymphalidae). Part II. Introduction and general comments, with a supplementary revision of the tribe. Zoologica, New York, 57: 1-40.

CRANE, J. 1957. Imaginal behavior in butterflies of the family Heliconiidae: changing social patterns and irrelevant actions. Zoologica, New York, 42: 135-145.

DeVries, P.J. 1987. The butterflies of Costa Rica and their natural history: Papilionidae, Pieridae, Nymphalidae. Princeton, Princeton Univ., 327p.

Downey, J.C. \& A.C. AlLYN JR. 1981. Chorionic sculpturing in eggs of Lycaenidae. Part I. Bull. Allyn Mus., Gainesville, 61: 1-29.

Fleming, H. 1960. The first instar larvae of the Heliconiinae (Butterflies) of Trinidad, W.I. Zoologica, New York, 45: 91-110.

GILBERT, L.E. 1971. Butterfly-plant coevolution: has Passiflora adenopoda won the selectional race with heliconiine butterflies? Science, New York, 172: 585-586.

1975. Ecological consequences of a coevolved mutualism between butterflies and plants, p. 210-240. In: L.E. GILBERT \& P.H. RAVEN (Eds). Coevolution of animals and plants. Austin, The University of Texas. XIII+246p.

GILBERT, L.E. 1991. Biodiversity of a Central American Heliconius community: pattern, process, and problems, p. 403-427. In: P.W. Price; T.M. LeWinsohn; G.W. Fernandes \& W.W. Benson (Eds). Plant-animal interactions: evolutionary ecology in tropical and temperate regions. New York, John Wiley \& Sons, 639p.

Hinton, H.E. 1981. Biology of Insect Eggs. London, Pergamon, Vol. 1, XXIII+473p.

Holzinger, H. \& R. Holzinger. 1994. Heliconius and related genera. Venette, Sciences Nat., 328p.

Lee, C.S.; B.A. McCool; J.L. Moore; D.M. Hillis \& L.E. GilberT. 1992. Phylogenetic study of heliconiine butterflies based on morphology and restriction analysys of ribosomal RNA genes. Zool. Jour. Linn. Soc., London, 106: 17-31.

MaLlet, J. 1986. Gregarious roosting and home range in Heliconius butterflies. Natl. Geogr. Res., Gaithersburg, 2: 198-215.

MilLER, J.S. 1991. Cladistics and classification of the Notodontidae (Lepidoptera: Noctuoidea) based on larval and adult morphology. Bull. Amer. Mus. Nat. Hist., New York, 204: 1-230.

Mosher, E. 1916. A classification of the Lepidoptera based on characters of the pupa. Bull. Ill. St. Lab. Nat. Hist., Urbana, 12: 1-165.

Mugrabi-Oliveira, E. \& G.R.P. Moreira. 1996a. Conspecific mimics and low host plant availability reduce egg laying by Heliconius erato phyllis (Fabricius) (Lepidoptera: Nymphalidae). Revta bras. Zool., Curitiba, 13: 929-937.

1996b. Size of and damage on shoots of Passiflora suberosa (Passifloraceae) influence oviposition site selection of Heliconius erato phyllis (Fabricius) (Lepidoptera: Nymphalidae). Revta bras. Zool., Curitiba, 13: 939-953.

PENZ, C.M. 1999. Higher level phylogeny for the passion-vine butterflies (Nymphalidae: Heliconiinae) based on early stage and adult morphology. Zool. Jour. Linn. Soc., London, 127: 277-344.

Peterson, A. 1962. Larvae of insects. An introduction to Neartic species. Part I. Lepidoptera and plant infesting Hymenoptera. Michigan, Edwards Brothers Inc. Ann Arbor, 315p.

SNedeCor, G.W. \& W.G. Cochran. 1980. Statistical methods. Ames, Iowa State Univ., 507p.

SPENCER, K.C. 1988. Chemical mediation of coevolution in the Passiflora-Heliconius interaction, p. 167-240. In: K.C. SPENCER (Ed.), Chemical mediation of coevolution. San Diego, Academic Press Inc, $609 \mathrm{p}$.

STEHR, F.W. 1987. Order Lepidoptera, p. 288-305. In: F.W. STEHR (Ed.). Immature insects. Dubuque, Kendall/Hunt, Vol. 1, XII+754p.

TAVARES, M.; L.A. KAMINSKI \& G.R.P. MoReira. 2002. Morfologia externa dos estágios imaturos de heliconíneos neotropicais: II - Dione juno juno (Cramer, 1779) (Lepidoptera: Nymphalidae: Heliconiinae). Revta bras. Zool., Curitiba, 19 (4): 961-976.

TURNER, J.R.G. 1971. Experiments on the demography of tropical butterflies. II. Longevity and home-range behavior in Heliconius erato. Biotropica, Washington, DC, 3: 21-31.

Recebido em 02.1.2002; aceito em 11.IX.2002. 